
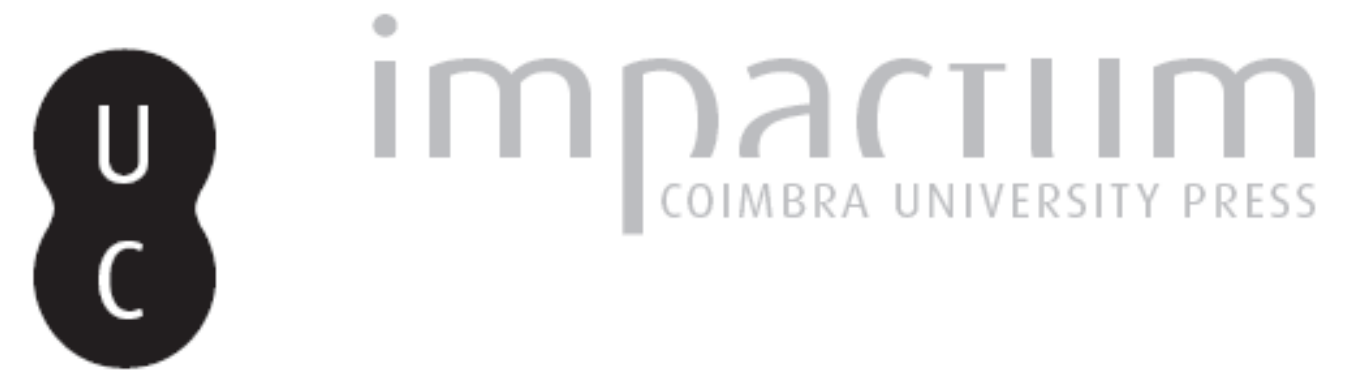

\title{
Inquirições, confirmações e registos da chancelaria régia portuguesa: notas para o seu estudo
}

\author{
Autor(es): $\quad$ Gomes, Saul António
}

Publicado por: Centro de História da Sociedade e da Cultura

URL persistente:

URI:http://hdl.handle.net/10316.2/39428

DOI:

DOI:http://dx.doi.org/10.14195/1645-2259_12_7

Accessed : $\quad$ 26-Apr-2023 07:59:02

A navegação consulta e descarregamento dos títulos inseridos nas Bibliotecas Digitais UC Digitalis, UC Pombalina e UC Impactum, pressupõem a aceitação plena e sem reservas dos Termos e Condições de Uso destas Bibliotecas Digitais, disponíveis em https://digitalis.uc.pt/pt-pt/termos.

Conforme exposto nos referidos Termos e Condições de Uso, o descarregamento de títulos de acesso restrito requer uma licença válida de autorização devendo o utilizador aceder ao(s) documento(s) a partir de um endereço de IP da instituição detentora da supramencionada licença.

Ao utilizador é apenas permitido o descarregamento para uso pessoal, pelo que o emprego do(s) título(s) descarregado(s) para outro fim, designadamente comercial, carece de autorização do respetivo autor ou editor da obra.

Na medida em que todas as obras da UC Digitalis se encontram protegidas pelo Código do Direito de Autor e Direitos Conexos e demais legislação aplicável, toda a cópia, parcial ou total, deste documento, nos casos em que é legalmente admitida, deverá conter ou fazer-se acompanhar por este aviso.

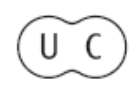


evista de História da Sociedade e da Cultura

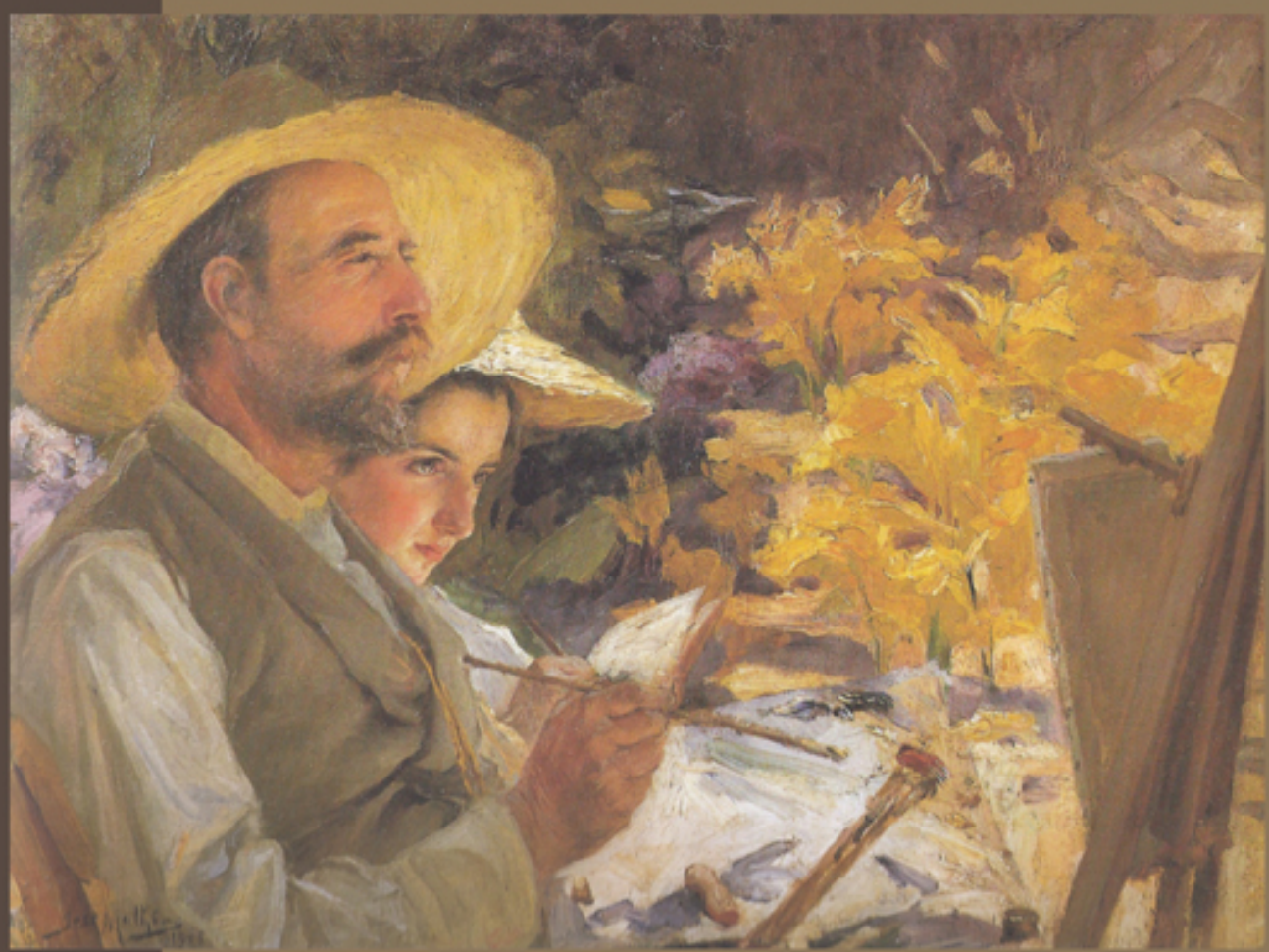

Centro de História da Sociedade e da Cultura Universidade de Coimbra 


\title{
Inquirições, confirmações e registos da chancelaria régia portuguesa: notas para o seu estudo
}

\author{
Saul António Gomes \\ Universidade de Coimbra \\ Centro de História da Sociedade e da Cultura da Universidade de Coimbra \\ sagcs@fl.uc.pt \\ Texto recebido em /Text submitted on: 01/03/2012 \\ Texto aprovado em /Text approved on: 19/04/2012
}

\section{Resumo/Abstract:}

Neste artigo pretende-se refletir acerca do processo de produção, de registo e de arquivamento, no contexto da chancelaria régia portuguesa, em especial a do reinado de D. Dinis (1279-1325), das inquirições levadas a cabo pelos monarcas seus antecessores. Sublinha-se o valor histórico plural deste género de fontes e reflete-se sobre as reformas arquivistas, medievais ou quinhentistas, a que este tipo de informação foi sujeito.

This article aims to focuses on the process of production, register and filling is studied, in the context of the Portuguese royal chancellery, in special of the reign of Dinis (1279-1325), of the taken inquiries the handle for the monarchs its predecessors. The plural historical value of this gender of sources and its influences on the reforms archivists, medieval or from de fifteenth century, the one that this type of information was subject

Palavras chave/Keywords:

Inquirições; D. Dinis; Chancelaria; Arquivo.

Royal inquires; King Denis; Chancellery; Archive. 
1 - Desde que, em 1888, a Academia das Ciências de Lisboa, na senda pioneira do trabalho de diplomatista de João Pedro Ribeiro', iniciou a edição das inquirições régias de D. Afonso II e D. Afonso III, de 1220 e 1258 , respetivamente, num processo que só se concluiria praticamente um século depois, em $1977^{2}$, que esta fonte tem vindo a merecer abundantes e reiteradas utilizações por parte dos historiadores ${ }^{3}$. Só muito recentemente, aliás, a Academia das Ciências de Lisboa relançou a edição de uma nova série desta tipologia documental, aberta com a publicação das Inquirições Gerais de D. Dinis, de $1284^{4}$.

As inquirições régias medievais portuguesas são, como se sabe, uma tipologia documental que, ontem como hoje, oferece múltiplos e sedutores recursos para a escrita da História. Extensas pelos largos espaços geográficos regionais que abrangem, estas fontes são, em boa verdade, muito fecundas para o historiador, sobretudo o contemporâneo, tão seduzido pelo quantitativo quanto pelo antropológico ${ }^{5}$.

As páginas por onde se explanam as Inquisitiones, que nos motivam, impressionam efetivamente pela abundância estatístico-económica dos dados que preservam, oferecendo, a quem as lê, elencos de direitos senhoriais e

1 Memorias para a Historia das Inquirições dos Primeiros Reinados de Portugal colligidas pelos discipulos da Aula de Diplomatica, Lisboa, Impressão Regia, 1815.

2 Portugaliae Monumenta Historica. Inquisitiones, (doravante citado por PMH) Vol. I, Parte I, Lisboa, 1888[-1897], Parte II, Lisboa, 1917[-1977]. Na edição destas Inquisitiones trabalharam João Pedro da Costa Basto, Sousa Monteiro, Anselmo Braamcamp Freire, Pedro de Azevedo, António Baião, Possidónio Mateus Laranjo Coelho e Rui de Azevedo. Vd. Portvgaliae Monvmenta Historica. Nova Série, Volume III. Inqvisitiones. Inquirições Gerais de D. Dinis. 1284 (Introdução, leitura e índices por José Augusto de Sotto Mayor Pizarro). Lisboa: Academia das Ciências de Lisboa, 2007, p. XII.

3 Vd. MARQUES, A. H. de Oliveira - Guia do Estudante de História Medieval Portuguesa, Lisboa, Editorial Estampa, 3ª edição, 1988, p. 167 e 192-194.

4 Portvgaliae Monvmenta Historica. Nova Série, Volume III. Inqvisitiones.., cit..

5 Assunto bem exemplificado, por exemplo, no estudo de KRUS, Luís - Escrita e Poder: as Inquirições de Afonso III. Passado, memória e poder na sociedade medieval portuguesa - Estudos. Redondo: Ed. Patrimonia, 1994, p. 35-57; MATTOSO, José; KRUS, Luís; BETTENCOURT, Olga - As Inquirições de 1258 como fonte da história da nobreza - o julgado de Aguiar de Sousa. Revista de História Económica e Social, Lisboa, nº 9 (1982), 17-74); MATTOSO, José; KRUS, Luís; ANDRADE, Amélia - Paços de Ferreira na Idade Média: uma sociedade e uma economia agrárias. Paços de Ferreira. Estudos Monográficos. Paços de Ferreira: Câmara Municipal de Paços de Ferreira, 1986, p. 171-243; MAURÍCIO, Maria Fernanda - Entre Douro e Tâmega e as Inquirições Afonsinas e Dionisinas. Lisboa: Colibri, 1997. 
realengos sobre propriedades rurais ou mesmo urbanas - como sucede, por exemplo, para o Entre Douro e Minho, Trás os Montes, grande parte da Beira Alta, os bispados de Lamego e de Viseu, ou, mais especificamente, as terras e centros urbanos de Seia, Gouveia, Coimbra e outras povoações da antiga Estremadura ${ }^{6}$-, sobre censos e obrigações fiscais, sobre padroados e direitos legítimos ou apropriações ilegais, para além de ordenar numerosas pequenas histórias e memórias de gentes e de lugares. São, efectivamente, documentos possuidores de níveis de informação histórica muito atrativos para qualquer medievalista.

Conservam-se as inquirições régias medievais portuguesas em vários volumes ou livros de chancelaria no Arquivo da Torre do Tombo, todos ou praticamente todos eles cópias em registo codicológico das atas originais que, na maior parte, se perderam ou foram sendo substituídas por novas lições e mesmo, em alguns casos, por traduções do latim à língua vernacular.

As inquisitiones conheceram, com D. Afonso II, o seu surto fundacional e também aquele que se revelou mais eficaz pela organização diplomática que o serviu e lhe consolidou o estilo processual e o método judicial. A importância deste projecto inquiricional afonsino fica bem demonstrada, aliás, pelo facto

6 Inquirições nos julgados do Porto, Maia, Refojos, Aguiar de Sousa, Penaguião, Baião e Soalhães (TT - Gaveta I, Mº 7, No 20); julgados de Arouca, Cambra e Fermedo (TT - Gaveta VIII, $\mathrm{M}^{\mathrm{o}}$ 4, Doc. 7), Coimbra e lugares da sua diocese (TT - Gaveta III, $\mathrm{M}^{\mathrm{o}}$ 10, Doc. 17; Inquirições de D. Afonso II, Livro 2, fls. 118v-124; Leitura Nova, Direitos Reais, Livro 2, fls. 47v-57v; Gaveta VIII, Mำ 2, Doc. 3). Inquirições publicadas, em parte, nos Portugaliae Monumenta Historica, e, mais dispersamente, por autores como: RIBEIRO, João Pedro - Memórias para a História das Inquirições..., p. 29-32 et passim; OLIVEIRA, Miguel de - Inquirições de D. Afonso II na Terra de Santa Maria. Arquivo do Distrito de Aveiro. Vol. II (1936), 71-74; BORRALHA, Conde da - Inquirições de D. Afonso II no Distrito de Aveiro. Arquivo do Distrito de Aveio. Vol. II (1936), 243-244 e 285-291; MADAHIL, António Gomes da Rocha - Milenário de Aveiro. Colectânea de Documentos Históricos. Vol. I (959-1516). Aveiro: Câmara Municipal de Aveiro, 1959, Doc. 33, p. 56-66; MATTOSO, José; KRUS, Luís; ANDRADE, Amélia - A Terra de Santa Maria no Século XIII: problemas e documentos. Sem local: Comissão de Vigilância do Castelo de Santa Maria da Feira. 1993, Doc. 8, p. 37-45, 107-108; GOMES, Saul António - As Ordens Militares e Coimbra medieval: tópicos e documentos para um estudo. In FERNANDES, Isabel Cristina (Coord.). Ordens Militares: Guerra, Religião, Poder e Cultura. Actas do III Encontro sobre Ordens Militares. Vol. II. Lisboa: Ed. Colibri - Câmara Municipal de Palmela, 1999, p. 50-65; SARAIVA, José - Inquirições de D. Denis. Arquivo Histórico de Portugal. Vol. I (1932-1934), 125-132, 264-270; Vol. II (1935), 113-126. 
de a sua estruturação servir de base e de orientação metodológica a outras inquirições régias levadas a cabo nos reinados posteriores.

A solidez do processo inquiricional, gerido pelos oficiais da escrita e chancelaria de D. Afonso II, impõe-nos reconhecer que é neste reinado que encontramos os testemunhos mais precoces e evidentes das mutações reformadoras e atualizadoras por que passavam os processos de produção documental oficial em Portugal ${ }^{7}$, para além de denotar a elevada complexidade organizacional e produtiva que então atingiu a chancelaria régia portuguesa ${ }^{8}$.

2 - Nas Inquirições Gerais de 1220, o texto, tal qual se preservou - e chegou-nos incompleto -, é uma composição organizada de acordo com princípios arquivísticos. A estruturação é quadripartida pelo "registrum de regalengis", passando depois aos "foris et dadivis de unaquaque collatione", à "noticia ecclesiarum tocius Bracharensis Archiepiscopatus de quibus dominus Rex est patronus vel non" dando lugar, por fim, à enunciação "de quanto habent ordines in unaquaque collatione". Antecede toda esta formulação uma notícia histórica breve e objectiva que elucida o leitor acerca da comissão responsável pela aplicação do inquérito:

7 Vd. GOMES, S. A. - In limine conscriptionis. Documentos, chancelaria e cultura no Mosteiro de Santa Cruz de Coimbra (Séculos XII a XIV). Viseu: Palimage e CHSC, 2007, p. 625-637; NOGUEIRA, Bernardo de Sá - Tabelionado e Instrumento Público em Portugal. Génese e implantação (1212-1279). Lisboa: Imprensa Nacional-Casa da Moeda, 2008, p. 7-12 et passim; SILVA, Maria João Oliveira e - Scriptores et notatores. A produção documental da Sé do Porto (1113-1247). Porto: Fio da Palavra, 2008, p. 133-135.

8 Cf. AZEVEDO, Rui de - O livro de registo da chancelaria de Afonso II de Portugal (1217-1221). Anuario de Estudios Medievales. No 4 (1967) 35-74; COSTA, Avelino de Jesus da - La Chancellerie royale portugaise jusqu'au milieu du XIII ${ }^{\mathrm{e}}$ siècle. Estudos de Cronologia, Diplomática, Paleografia e Histórico-Linguísticos. Porto: SPEM, 1992, p. $135-$ -164; SANTOS, Maria José Azevedo - A Chancelaria de D. Afonso II (1211-1223). Teorias e Práticas. Ler e Compreender a Escrita na Idade Média. Lisboa: Edições Colibri e Faculdade de Letras de Coimbra, 2000, p. 11-58; VILAR, Hermínia Vasconcelos - Do arquivo ao registo: o percurso de uma memória no reinado de Afonso II. Penélope. Revista de História e Ciências Sociais. Número 30/31, (2007) 19-50; GOMES, S. A. - Identidade e memória na Chancelaria real Portuguesa na Idade Média. Raizes Medievais do Brasil Moderno. Actas. 2 a 5 de Novembro de 2007. Lisboa: Academia Portuguesa da História. 2008, p. 67-96. 
"Hec sunt Inquisitiones de Regalengis de termino Vimaranensi et de aliis Judicatibus inferius scriptis, quas fecerunt abbas Sancti Tirsi, abbas Polumbarii, et prior Vimaranensis, et prior de Costa, et prior Sancti Torcati, et Gomecius de Rupella, et magister Menendus frater Costensis, et judex Ramirus Petri, et Johannes Petri villanus, et Fernandus Dominici, et Martinus Stephani, et tabellio Martinus Martini, per mandatum domini Regis Alfonsi, filii domini Regis Sancii, et fuerunt facte in mense Augusti sub Era $M^{a} C C^{a} L^{a} V I I I^{a} . " 9$

A comissão mandatada pelo rei era constituída, como vimos, por clérigos e por leigos. Secretariou-a o tabelião régio Martinho Martins. Para um inquérito que se estenderá por terras e julgados situados no âmbito geográfico da arquidiocese bracarense, é significativo que o clero chamado ao "mandato" régio seja, para além do prior de Santa Maria de Guimarães, essencialmente regular - os abades beneditinos de Santo Tirso e de Pombeiro e alguns cónegos regulares dos Mosteiros da Costa e de S. Torquato - a que se juntaram os leigos Ramiro Peres, juiz, João Peres, Fernando Domingues e Martinho Esteves.

O discurso escrito distribui-se por capitula os quais, no registo manuscrito usado pelos editores do texto nos Portugaliae Monumenta Historica, são antecedidos por caldeirões ou sinais paleográficos de parágrafo. Tenhamos presente que o manuscrito que serviu aos editores não é um original da chancelaria de D. Afonso II.

3 - Cumpre refletir que estas inquirições régias dão continuidade a uma apreciável experiência redativa em ambientes forenses. Não destoam, aliás, de outros exercícios de escrita em chancelarias reais estrangeiras, mormente a catalã, na qual se encontram, já para a segunda metade do século XII, abundantes registos de computa fiscais, de registos memoriais acerca das honras, dos rendimentos e dos usos que beneficiavam a respetiva coroa, numa estrutura próxima do teor das inquirições que nos ocupam ${ }^{10}$.

9 PMH-Inquisitiones, I, Tom, 1, p. 1.

${ }^{10} \mathrm{Vd}$. BISSON, Thomas N. - Fiscal accounts of Catalonia under the early count-kings (1151-1213). 2 vols.. Berkeley: Universidade da Califórnia, 1984. 
Tenhamos presente que os anos de entre 1150 e 1250, em Portugal, foram pródigos em conflitualidade legal, sobremodo, mas não apenas, nos circuitos endógenos à Ecclesia. Compreende-se bem, face a essa realidade, o papel histórico jurisprudencial protagonizado por um papa como Inocêncio III (1198-1218) ${ }^{11}$. Desde cedo, caso bem ilustrado entre nós, que as estruturas administrativas eclesiásticas desenvolveram métodos de colheita e de armazenamento de informação complexa e de amplo espectro geográfico. Os rolos ou censuais da Sé de Braga, dos séculos XI e XII, por exemplo, prefiguram, de algum modo, a lógica formal que virá a ser seguida nas inquisitiones reais ducentistas; um critério geográfico abrangente seguido por uma indicação simples e pura dos censos devidos por cada entidade.

Nesses censuais de mitras e de catedrais, o discurso formal é, em geral, meramente enumerativo e não conhece preâmbulos ou titulações subjetivas. Só raramente se foge a este padrão, como sucede no censual das Terras de Guimarães e de Montelongo, de 1259, obra já de uma metodologia própria dos discursos tabeliónicos do tempo, onde lemos:

"Hec est noticia de hiis que dantur et debent dari de ecclesiis de terra de Vimaranis capitulo Bracharensi scilicet Garsias Petri rector ecclesie de Villa Nova de Inffantibus, Petrus Martini rector ecclesie de Pineyro, Dominicus Johannis rector ecclesie de Avezam et Suerius Petri commendator ecclesie de Polvereira, omnes ad sancta Dei evangelia jurati dixerunt quorum dicta ego Johannes Petri publicus tabellio Bracharensis, de mandato et de auctoritate domni Petri Pelagii et domni Pelagii Menendi canonicorum ecclesie Bracharensis ejusdem archiepiscopi visitatorum in publicam formam reddegi. III ${ }^{\circ}$ kalendas Octobris Era $M^{a} C C^{a} X_{C V I I}{ }^{\infty} 12$.

A experiência redaccional das chancelarias eclesiásticas portuguesas, principalmente a bracarense ${ }^{13}$, como sabemos, é a pródiga fonte que

${ }^{11}$ Vd. COSTA, Avelino de Jesus da, MARQUES, Maria Alegria - Bulário Português, Inocêncio III (1198-1216). Coimbra: INIC,1989.

${ }^{12}$ COSTA, Avelino de Jesus da - O Bispo D. Pedro e a organização da Diocese de Braga. Vol. II. $2^{\text {a }}$ ed., Braga: Irmandade de S. Bento da Porta Aberta, 2000, p. 232.

${ }^{13}$ Cf. CUNHA, Cristina Almeida e - A Chancelaria do Arcebispado de Braga (1071-1245), (Dissertação de Doutoramento policopiada). Porto: Faculdade de Letras da Universidade do Porto, 1998; MORUJÃO, Maria do Rosário Barbosa - A Sé de Coimbra: 
enformará o estabelecimento e a evolução institucional das chancelarias dos nossos primeiros monarcas. As inquisitiones do Reino de Portugal constituem um texto singular na aula diplomatica que é a chancelaria régia. A sua estruturação formal, em D. Afonso II, revela um discurso muito distante da tradição retórica própria do acto régio escrito.

4 - Devemos recordar, assim sendo, que as inquirições do rei D. Afonso II estão compiladas em três livros, as do rei D. Afonso III em 9 livros e, mais tardias, situadas entre os anos de 1288 e 1307, as de D. Dinis, estas distribuídas por 10 livros. Anote-se, por outro lado, que existem vários cadernos de inquirições de 1284 apensos ao livro $2^{\circ}$ das inquirições de D. Afonso $\mathrm{III}^{14}$. As conhecidas inquirições de D. Afonso IV, correspondentes aos livros 1 e 2 da Chancelaria desse monarca não se integram verdadeiramente na estrutura diplomática ou institucional das anteriores, dado que são um corpus específico relativo às dissensões entre o rei e o senhorio episcopal do burgo portuense ${ }^{15}$.

De um modo geral, já aquando do início da publicação destas inquirições nos Portugaliae Monumenta Historica se estabeleceu que estes livros correspondem a cópias, como escrevemos, organizadas sobremodo debaixo da chancela de D. Dinis, em especial entre finais da década de 1280 e inícios da de 1300. São, por esse facto, enquanto fontes documentais, testemunhas de si próprias, isto é, devem ser vistas primeiramente na sua realidade documental e arquivística de composições textuais codicológicodiplomáticas, resultantes de uma cópia que resultou de uma organização escriturística controlada a partir da chancelaria real dionisina.

a Instituição e a Chancelaria (1080-1318). Lisboa: Fundação Calouste Gulbenkian e Fundação para a Ciência e a Tecnologia, 2011; SILVA, Maria João Oliveira e - Scriptores et notatores: a produção documental da Sé do Porto (1113-1247). Porto: Fio da Palavra, 2008; Idem - A Escrita na Catedral: a chancelaria episcopal do Porto na Idade Média (Estudo Diplomático e Paleográfico). (Dissertação de Doutoramento; policopiada). Porto: Faculdade de Letras da Universidade do Porto, 2010.

${ }^{14}$ Vd. Portvgaliae Monvmenta Historica. Nova série. Vol. III. Inqvisitiones..., cit.

${ }^{15}$ MARQUES, A. H. de Oliveira-Guia do Estudante de História Medieval Portuguesa, cit., p. 192-194. 
5 - As inquirições de D. Afonso II, como referimos, chegam-nos em três livros ou registos, nenhum deles original ou primitivo. O registo ou manuscrito mais antigo é o Livro V das Inquirições de D. Dinis (que chegou a ser conhecido por Registo de Guimarães ou Livro do Padrom), concluído em 1289 , conforme o cólofon que apresenta no fólio final, assinado pelo tabelião vimaranense Pedro Domingues, no qual podemos ler o seguinte dictum:

"Ego autem Petrus Dominici publicus tabellio Vimarenensis de mandato excellentissimi domini Domni Dionisii regis Portugaliae et Algarbii hoc registrum conscripsi et exinde hoc librum confeci et hoc signum meum apposui in eodem in testimonium veritatis.

Actum Vimaranis, iiij ${ }^{a}$ kalendas Aprilis. Era $M^{a} . C C C^{a} . X X^{a} . V_{i j}^{a} . "$ (Livro I, fl. 135).

Neste dito "Livro V de D. Dinis", o cólofon reproduzido vem autenticado pelo sinal público do tabelião. Este livro, contudo, foi considerado pelo editor das Inquirições de 1220 inseridas nos Portugaliae Monumenta Historica, João de Sousa Basto, do ponto de vista do seu teor e tradição textual, como menos organizado do que a versão que aparece no Livro I das Inquirições de D. Afonso II. Este Livro I copia o anterior indo ao pormenor de reproduzir fielmente o cólofon antes citado. Mas a informação que apresenta é mais completa do que aquela que se encontra no Livro V ou do "Padrom".

O Livro I das Inquirições foi realizado, naturalmente, depois de 1289, data em que se fixou a cópia do Livro $\mathrm{V}$ enunciado. $\mathrm{O}$ seu cuidado em manter-se fiel ao Livro V vai ao pormenor de reproduzir o cólofon tabeliónico nosso conhecido, posto que se abstenha de imitar o sinal de autenticidade de Pedro Domingues. Mas as suas características paleográficas e o próprio conteúdo textual, integram-no na tradição gráfica do reinado dionisino. Não deve tratar-se, na verdade, de reprodução muito distante do ano citado.

De um ponto de vista textual, como fica escrito, a versão "Livro I das Inquirições" apresenta-se como mais completa, mais organizada, menos confusa e menos lacunar do que a da versão preservada no manuscrito subscrito pela mão do tabelião Pedro Domingues.

Há que reconhecer, entretanto, que ambos os códices são compilações realizadas em ambiente arquivístico e, decerto, como ato de intencionalidade arquivística de acordo com um padrão cultural medievo que se preocupava, bem mais profundamente do que vulgarmente se poderá julgar, com a 
preservação documenta ${ }^{16}$. Tal como se apresentam não podem deixar de resultar tanto de um projeto arquivístico reformador desenvolvido pela chancelaria de D. Dinis, quanto, provavelmente, dão corpo à necessidade de uma informação mais centralizada ou unificada, de um ponto de vista do suporte textual, que certamente os inquiridores dionisinos necessitavam para as missões inspetivas que lhes haviam sido confiadas pelo monarca.

O aparecimento de tabeliães públicos, de Lisboa, como de Guimarães ou de Leiria, senão de outras vilas e cidades, associados ao serviço, ocasional ou mais permanente ${ }^{17}$, da chancelaria de D. Dinis - como se atesta noutros livros desse reinado, que comprovam a existência de um serviço efetivo e autorizado de escrita em registo de chancelaria, que vai ao ponto de autenticarem nas colunas dos livros originais os lançamentos dos atos que neles efetuavam por sua própria mão ${ }^{18}$ - é uma questão do maior interesse diplomático, tanto quanto histórico, uma vez que, ao abrir-se o trabalho da aula diplomatica palatina à participação notarial externa, isso vem indiciar que a chancelaria régia portuguesa desse tempo parece organizar-se como

${ }^{16}$ Vd. ERHART, P. - "Carta ista amalfitana est et nescitur legere”. The charters of Carva dei Tirreni and St Gall and their evidence for early medieval archival practice. Gazette $d u$ Livre Médiéval, № 50, (Printemps, 2007).[Disponível em: http://www.palaeographia.org/glm/ art/erhart2.htm (consulta em 13.12.2007)). Vd. AZEVEDO, Pedro de, e BAIÃO, António O Archivo da Torre do Tombo. Sua historia, corpos que o compõem e organização. Lisboa: Annaes da Academia de Estudos Livres, 1905 [nova edição, Lisboa, 1990]; SANTOS, Maria José Azevedo - As condições de conservação dos documentos e dos livros em Portugal (Séc. XII-XV). Estudos de Diplomática Portuguesa. Lisboa: Ed. Colibri e Faculdade de Letras da Universidade de Coimbra, 2001, p. 233-256; GOMES, Saul António - In limine conscriptionis..., p. 241 e seguintes; IDEM - O "Inventário das Escrituras" do Convento de S. Francisco de Santarém de [1411]. Observações breves acerca da praxis arquivística medieval portuguesa. Revista de História da Sociedade e da Cultura, 3 (2003 [2004]) 263-292; Idem - "DONATIONES CVSTODIANTVR: DONATIONES SERVENTVR". Da memória e praxis arquivística do Mosteiro de Santa Maria de Alcobaça em tempos medievais. Humanitas, 57 (2005) 245-269.

${ }^{17}$ Cf. NOGUEIRA, Bernardo de Sá - Lourenço Eanes, tabelião de Lisboa (1301-1332). Reconstituição e análise do seu cartório. (Tese de mestrado policopiada). Lisboa: Faculdade de Letras da Universidade de Lisboa, 1988.

${ }^{18}$ Caso detetável, por exemplo, com Miguel Eanes, público tabelião de Leiria que, a rogo de D. João de Alprão, chanceler régio, averba, com a data de 30 de Novembro de 1280 , encontrando-se justamente em Leiria, em livro da Chancelaria de D. Dinis, com desenho do respetivo sinal público de autenticação, o registo da carta de apresentação de um clérigo na igreja de S. Miguel de Fiães, do padroado real. (Direção Geral dos Arquivos Nacionais / Torre do Tombo (doravante referido por TT) - Chancelaria de D. Dinis, Livro 1, fls. 281-281v). 
que num universo complexo, em que a produção documental e o seu registo arquivístico eram tarefas partilhadas a diferentes níveis geográficos, funcionais e de responsabilidade jurídica senão mesmo política.

Não cumpre, contudo, aprofundar aqui esta matéria, mas tão-somente avocá-la para uma contextualização histórica da memória pressuposta pelos registos inquiricionais ducentistas portugueses. Importará acentuar, nesta questão, que os elementos em análise nos levam a equacionar a atitude régia neste processo. Constituindo os apógrafos dionisinos das inquirições de D. Afonso II, como vemos, um ato de atualização e de normalização ou de clarificação da memória burocrática régia nesta matéria, isso deverá compreender-se primeiramente como ato próprio de um foro organizacional e funcional arquivístico, ou seja, como uma atitude custodial, mais do que como restabelecimento, por tais traslados, de uma validade forense probatória no tempo em que se concretizaram tais reproduções.

Naturalmente, os oficiais da chancelaria régia responsáveis pela renovação desses registos não terão sido juízes ou notários participantes, no terreno, das alçadas inquiricionais. Mesmo considerando a relevância de um levantamento da informação arquivística acerca das antigas inquirições de 1220 e 1258, por D. Dinis, no contexto das novas inquirições que ele mesmo promoverá para exercer a sua soberania no Regnum, como sobressai das inquirições de 1288 e anos seguintes, os traslados em causa deverão justificar-se em primeira mão sob o princípio da historicidade arquivística que, nos séculos medievais, orientava atos de renovatio scripturarum.

6 - Em síntese, seja no dito "Livro V de D. Dinis", seja no Livro I de D. Afonso II, como fica dito, estamos perante cópias.

Escreveu o tabelião responsável pela versão mais antiga, a do Livro V, que "hoc registrum conscripsi et exinde hoc librum confeci", ou seja, numa tradução mais do sentido do que literal, "compilei este registo e então escrevi este livro". A ideia é, aqui, mais a de alguém que gera, organiza e controla o processo de uma cópia do que a de um simples amanuense ou serviçal copista.

Na base desse trabalho, necessariamente, estiveram os livros primeiros dos inquéritos, os quais deram expressão codicológica a atas originais 
subscritas pelas comissões ou alçadas que foram depositadas no arquivo régio. Conhecem-se algumas dessas "atas primitivas" ou originais, subsistentes sob a forma de pequenos cadernos ou mesmo de tiras de antigos rolos. Chegam-nos tais atas fragmentariamente e incompletas, desconhecendo-se por via de regra as datas exatas em que foram elaboradas. A análise das mesmas, contudo, leva-nos a propor-lhes uma datação crítica que cai ainda no final do reinado de D. Afonso $\mathrm{II}^{19}$.

Por outro lado, devemos sublinhar que o texto tal qual se encontra no Livro I das Inquirições, que vimos referindo, recolhe uma ampliação dessas primitivas inquirições datada de 3 de Janeiro de 1251. De facto, no fólio $126 v^{\circ}$ lemos a indicação de que na "Era $M^{a} C C^{a} L x x x^{a}$ ix $x^{a}$ tribus diebus Januarii fuerunt M. Pelagii cantor Vimaranensis et J. Martini judex et $V$. Martini scriba inquirere Regalengos et hereditates fora de termino de Celorico per mandatum domini regis Alfonsi et Comitis Bolonie." Esta nova inquirição foi, como se refere, incorporada no corpus das inquirições anteriores de 1220, com elas se entrosando de forma explícita e histórica e arquivisticamente significativas.

Atentemos no facto de os resultados desta inquirição de inícios de 1251 terem sido confrontados com os de um livro ou registo preexistente. Isso torna-se muito claro quando se alude, por exemplo, às freguesias de S. Pedro das Ferrarias ("Dixerunt idem per omnia sicut alii jurati de primis Registris" (fl. 127)), de Santa Maria de Canedo ("Et ista pausa non erat scripta in primo Registro" (fl. 127)), de S. João de Covas ("Et ista parrochia non est scripta in primo Registro" (fl. 127) ou de S. Miguel de Carcerilhe ("Et iacet in Registro primo quod Menendus Garsie debet leuare conductum domino terre. (...) Et ita iacet in registro primo et debet portario uocem et calumpniam") (fl. 128).

Este "registo primo" será o mesmo que vem citado como "registro veteri" no parágrafo acerca da freguesia de Santiago de Ourelhe: "Et sedet in Registro veteri quod Pelagius Mauranus destruxit illam (...). Isti sunt qui debent esse maiordomi et non sedent in primo Registro. (...) Et isti debent

${ }_{19}$ Vd. TT - Gaveta I, M $7, \mathrm{~N}^{\mathrm{o}} 20$ e $\mathrm{M}^{\mathrm{o}} 2, \mathrm{~N}^{\mathrm{o}} 18$; Gaveta III, $\mathrm{M}^{\mathrm{o}} 10, \mathrm{~N}^{\mathrm{o}} 17$; Gaveta VIII, $\mathrm{M}^{\mathrm{o}} 2, \mathrm{~N}^{\mathrm{o}} 3$ e $\mathrm{M}^{\mathrm{o}} 4, \mathrm{~N}^{\mathrm{o}} 7$. 
esse maiordomi de Aries et filii et nepotes eorum qui sunt scripti in Registro veteri debent esse maiordomi quilibet in foro suo." (fl. 127 $\left.\mathrm{v}^{\circ}\right)$.

Reconheceremos que este tipo de informação pressupõe a verificação do "registo velho", trabalho certamente levado a cabo em arquivo, depois do ato inquiricional realizado - não creio, na verdade, que as comissões levassem consigo os registos primeiro ou velho, ou seja, originais -, pelo que a sua consideração impõe aceitarmos que o texto em causa corresponde a um mundum, ou passagem a forma definitiva executada em fase posterior, e com base no cruzamento entre a informação registada no arquivo real e a informação atualizada trazida pelos inquiridores ${ }^{20}$.

A cópia do tabelião dionisino, Pedro Domingues, realizou-se, como vemos, sobre um texto ou volume que integrava um "registo velho" e os aditamentos de 1251. Mas só um exame mais minucioso nos permitirá ter mais certezas quanto à consideração da questão da origem e tradição textual dos atos utilizados pelo mencionado tabelião vimaranense, em 1289, se o "registo primo", se as atas originais - que, como se comprova pelo que chegou aos nossos dias, se mantinham seguramente no arquivo real ou se ambos.

7 - Uma nova e profunda alteração no corpus das inquirições ducentistas de D. Afonso II - como ainda nas de 1258, cuja menção aqui é oportuna porquanto ajuda a esclarecer mais aprofundadamente o destino arquivístico daquelas - sucedeu nos inícios da segunda década do século XVI.

Vêm estas considerações a propósito do Livro II das Inquirições de D. Afonso II. Este livro é cópia, decerto também da época dionisina, do citado Livro I. Nele, contudo, emergem diversas anotações quinhentistas que demonstram o quanto os manuscritos medievos deste género documental sofreram pela aplicação, por parte de oficiais ao serviço da Leitura Nova patrocinada pelo rei D. Manuel, de critérios de eliminação de acervos documentais.

${ }^{20}$ Os inquiridores que registaram esta informação, como outros seus antecessores, foram confrontados com a existência de documentos afirmados como autênticos e preservados em arquivos familiares ou pessoais mencionados pelos inquiridos ("Et filii de Fafila dixerunt quod habebant cartam regis per quam non debent esse forarii et nos inquisitores non uidimus illam." (fl. 127vo)). 
No primeiro fólio desse Livro II, um copista quinhentista comentou ser códice repetitivo e, quiçá, inútil aos traslados para os belos volumes da Leitura Nova, porquanto nada acrescentava de substancial ao que vinha no Livro I: “(...) ate honde estaa apontado pelo bacharel Pedro Alvarez que o comcertou porque ha hy outro tall como este aatee o ditõ synall (...)”. $\mathrm{Na}$ folha 134, a mesma mão quinhentista declarará estar tudo "comcertado atee qui com a letera nova per mym Fernam das Nãos (?) com o Senhor Licenciado Gabriell Gyll."

Como se verifica, o Livro I como o II das Inquirições do Senhor D. Afonso II foram alvo de "conserto", entenda-se verificação e validação, justamente por alguns dos responsáveis pela Leitura Nova manuelina, destacando-se, entre eles, o nome de Gabriel Gil. O Livro I, por exemplo, viu apor-se-lhe um conjunto de bifólios contendo índices divididos em quatro títulos que mais não fazem do que aclarar em nova letra a tetrarquia de organização de conteúdos que o códice apresentava já desde os tempos dionisinos senão mesmo primitivos:

"Inquirições dos reguenguos casaes foros e dadivas rendas e direitos que el Rey tem nas freguesias dos julgados e terras abaixo decraradas, as quaaes foram tiradas per mandado del Rei Dom Affomso ijo filho del Rei Dom Sancho, em o mes d'Agosto era de mil.CC. lviij annos. Primeiramente." (Fls. 1-2).

"Titullo das igrejas de que el Rei he padroeiro no arcebispado de Bragaa com as quaaes neste livro vãao de mestura as igrejas de que el Rei nam he padroeiro e nam emtram nesta tavoada." (Fls. 3-4).

"Titullo do que tem as igrejas e moesteiros em cada huna freguesia dos julgados e terras abaixo declaradas." (Fls. 5-5vº).

"Inquiriçom que se tirou sobre os reguemgos malladias e cousas que a el Rey tiinham sonegadas nos logares e freguesias dos julgados e terras abaixo declaradas." (Fls. 6-6vº).

No Livro II, contudo, não aparece este tipo de "tavoada", mas a portada inicial do códice abre, em letra da Leitura Nova, com a exposição seguinte:

"Livro de inquiriçoens da terra e termo de Guimarães e outras tiradas per mandado del Rey Dom Affonso filho del Rey Dom Sancho.J: na era de 1258. E no cabo deste livro estam outras inquirições dos direitos que el Rei ha nas terras d'Agueda e Vouga e em outros lugares." (Fl. 1). 
No fólio $109 \mathrm{v}^{\mathrm{o}}$ deste segundo manuscrito, à margem, junto ao início das inquirições da terra de Águeda e Vouga, o mencionado amanuense do arquivo real da Torre do Tombo, Pedro Lopes, averbou:

"Atee qui está concertado com o livro que tem huns coiros pretos e começa come este. E este [he] por escusado per neste se leerem alguãs freguesias que o outro tem. [E] que se mais freguesias neste e nom esta no outro livro aos xxbiij de Fevereiro de 1511. - Petrus. Esto daqui pera diamte se deve ... usar ao outro livro e o ajumtar e he pera encadernarem." (?).

Teve o citado Licenciado Gabriel Gil uma responsabilidade maior nos destinos arquivísticos das inquirições tanto de D. Afonso II, quanto das de D. Afonso III. No Livro I das Inquirições de D. Afonso III, em que se contém a terceira alçada relativa a toda a terra de Seia e Gouveia e seus termos, nos bispados de Lamego e Viseu até Trancoso. Por exemplo, Gabriel Gil inscreveu na abertura e no fecho desse códice a explicação seguinte, que é muito reveladora dos destinos dados aos registos originais ou primitivos que continham as inquirições ducentistas:

"Este livro foy concertado per mim o Licenciado Gabriel Gil que per espicial mandado del Rey nosso senhor tenho careguo de prover e comcertar toda a livraria deste Tombo o qual comcertey com outros dous livros do teor deste: hum dos quaes era esprito em papel de letra muy amtigua per que parecia ser o propeo original. E outro em purgaminho. E porque em todos tres se nom achou mais em hum que em outro quanto a sostancia, e o propio asy esprito em papel ser caduco em alguas partes e na fim dele falecerem certos cadernos e este com os correjimentos que se nele fezeram ao concertar foy avido por mais comprido e verdadeiro: se fez delle fundamento pera se dele usar e dar as partes o que lhes dele comprir e do outro esprito em purgaminho nom: nem do propeo esprito em papel que foy roto. E este he esprito em $C t^{o}$ lxxxb folhas. Fecto aos xij dias do mes de Junho de mil $b^{c} x i j$ annos. - Gabriel Licentiatus."

Também no Livro Terceiro de Inquirições de D. Afonso III se apresenta uma cópia desta terceira alçada da terra de Seia. $\mathrm{Na}$ sua postumeira lauda escreveu Gabriel Gil o seguinte apontamento:

"Este livro foy comcertado per mym Licenciado Gabriel Gil que per espicial mamdado del Rey nosso senhor tenho carreguo de prover 
e concertar toda a livraria deste Tombo o qual concertey com outros dous livros do teor deste hum dos quaes era esprito em papel de letra muy antigua que parecia ser o propeo original que por ser muy caduco em alguas partes e se nam poder ler e falecerem na fim dele certos cadernos foy loguo roto e outro ficou pera se dele usar e dar as parteso que thes dele comprir porque foy avido por mais cumprido e verdadeiro que este que fica por escusado. Feito aos biij dias do mes de Junho de mil bi xij anos. - Gabriel licentiatus" ${ }^{21}$.

Estas citações clarificam muito bem o destino dado aos registos mais antigos das inquirições de D. Afonso III, cuja matéria de suporte era o papel, tidos por caducos e inúteis e, por isso, "foram logo rotos", apenas sobrevivendo os registos em pergaminho. Não significa isto, naturalmente, que tais livros antigos relativos às inquirições do Bolonhês fossem os originais. É muito provável que assim não acontecesse, porquanto seria bastante anormal, na tradição da chancelaria real portuguesa anterior ao reinado de D. Dinis, o recurso ao papel como matéria de livros de registo, posto que devamos admitir que, com o Lavrador, tal prática deva ter sido vulgarizada.

8 - Consideremos que a chancelaria dionisina atuou também sobre os registos de inquirições de D. Afonso III $^{22}$. A reforma arquivística detetada para com as inquirições de D. Afonso II confirma-se igualmente para os textos inquiricionais do Bolonhês. O texto da segunda alçada, dedicada ao território situado entre o rio Douro e o Ave até ao Tâmega, apresenta duas redações.

A primeira lição, que é a mais antiga, foi recolhida no Livro $V$ de Inquirições de D. Afonso III. A segunda lição, extraída aparentemente a partir da anterior por um escriba chamado João Domingues, que averbou a conclusão dessa cópia no dia 18 de Setembro de 1302, integra um códice erroneamente

${ }^{21}$ Citações reproduzidas a partir da publicação da terceira alçada das inquirições de D. Afonso III (PMH - Inquisitiones, Vol. I, Parte II, 1917, página de abertura não numerada).

${ }^{22}$ Sobre o contexto cultural da chancelaria deste monarca, leia-se o recente estudo de VENTURA, Leontina e OLIVEIRA, António Resende - Os Livros do rei. Administração e cultura no tempo de D. Afonso III. Boletim do Arquivo da Universidade de Coimbra, XXV (2012), 181-194. 
intitulado de "Livro II de Inquirições de D. Afonso II", códice bastante maltratado, como alerta o editor dos Portugaliae Monumenta Historica, pela encadernação que levou em 1555: "Falta-lhe o primeiro caderno; o segundo encontra-se depois do terceiro, por onde o livro começa; e o ultimo foi desterrado para o fim do intitulado Livro IX de Inquirições de D. Diniz." ${ }^{23}$

Uma terceira cópia desta alçada aparece no livro da Leitura Nova dito de Inquirições de Entre Douro e Ave, tendo sido acabada em 22 de Junho de 1522.

Da primeira alçada das inquirições de D. Afonso III, estendida ao Entre Cádavo e Minho, compiladas no Livro IX das Inquirições desse monarca, suspeita-se que os depoimentos que aparecem em português devam corresponder a tradução para língua romance datável do primeiro terço do século XIV. Os depoimentos da quarta alçada, para o Entre Douro e Tâmega, Bragança e seus termos, foram traduzidos do Latim para o Português em 1331, já no reinado de D. Afonso IV. Nas suas páginas, D. Afonso III é citado frequentemente no passado, procurando os compiladores distingui-lo de seu pai: "D. Affonso Rei de Portugal e Conde de Bolonha".

9 - A história arquivística desses atos, necessariamente, não anula o efeito histórico da sua génese e redação. Reconheçamos que, no essencial, o período central de organização dessas Inquisitiones é, sobretudo, a Centúria ducentista que, em Portugal como por toda a Cristandade, se particulariza pelo desabrochar exponencial da vida intelectual e dos centros produtores de escrita. Chancelarias régias, como também nobiliárquicas, eclesiásticas diocesanas ou monásticas, como, ainda, municipais, prosperaram nesse século que em Portugal haverá de culminar, em termos de vida intelectual e cultural erudita, no estabelecimento, em 1290, do primeiro studium generale do Reino.

De qualquer modo, não queremos fechar este texto sem deixar de anotar que as considerações aqui expostas, se bem que não se estendam a uma análise de todos os casos, serão, ainda assim, suficientes para verificarmos

\footnotetext{
${ }^{23}$ PMH - Inquisitiones, Vol. I, Parte II, 1917, página de abertura não numerada.
} 
que a transmissão das inquirições régias de D. Afonso II e de seu filho D. Afonso III estiveram sujeitas a perdas, rescritas e mutações.

As inquirições ducentistas portuguesas são, por tudo o que refletimos, um texto arquivístico, uma recomposição construída no palco de uma chancelaria real profundamente interventora e invasiva no século XIV, sobremodo, mas não apenas, com D. Dinis. Elas são, ainda, em várias situações, um texto revisitado e recomposto que só depois de Quinhentos parece ter recebido o benefício da tranquilidade, que é pressuposto os documentos históricos encontrarem nos agostinianos "palácios da memória", a que dão lugar todos os arquivos públicos ou privados. 